\title{
Potential of hydrogen addition to natural gas or ammonia as a solution towards low- or zero- carbon fuel for the supply of a small turbocharged SI engine
}

\author{
Alfredo Lanotte ${ }^{1}$,Vincenzo De Bellis ${ }^{1}$ and Enrica Malfi ${ }^{1}$ \\ ${ }^{1}$ University of Naples Federico II
}

\begin{abstract}
Nowadays there is an increasing interest in carbon-free fuels such as ammonia and hydrogen. Those fuels, on one hand, allow to drastically reduce $\mathrm{CO}_{2}$ emissions, helping to comply with the increasingly stringent emission regulations, and, on the other hand, could lead to possible advantages in performances if blended with conventional fuels. In this regard, this work focuses on the 1D numerical study of an internal combustion engine supplied with different fuels: pure gasoline, and blends of methane-hydrogen and ammonia-hydrogen. The analyses are carried out with reference to a downsized turbocharged two-cylinder engine working in an operating point representative of engine operations along WLTC, namely $1800 \mathrm{rpm}$ and 9.4 bar of BMEP. To evaluate the potential of methanehydrogen and ammonia-hydrogen blends, a parametric study is performed. The varied parameters are air/fuel proportions (from 1 up to 2) and the hydrogen fraction over the total fuel. Hydrogen volume percentages up to $60 \%$ are considered both in the case of methane-hydrogen and ammoniahydrogen blends. Model predictive capabilities are enhanced through a refined treatment of the laminar flame speed and chemistry of the end gas to improve the description of the combustion process and knock phenomenon, respectively. After the model validation under pure gasoline supply, numerical analyses allowed to estimate the benefits and drawbacks of considered alternative fuels in terms of efficiency, carbon monoxide, and pollutant emissions.
\end{abstract}

\section{Introduction}

In recent years, $\mathrm{CO}_{2}$ emissions have dramatically increased leading to a heavy growth in global warming. In 1997 several countries have signed the Kyoto Protocol [1] by which they committed themselves to reduce greenhouse emissions within acceptable values. For the same purpose in 2015, the Paris climate agreement has been signed [2] which aims to keep global warming below 2 degrees Celsius and strives to limit it to 1.5 degrees Celsius. In the last few years, the interest in carbon-free fuels, as ammonia and hydrogen, is rapidly growing in order to reduce greenhouse emissions as soon as possible and also to comply with the new stringent regulations in the transport and energy production sectors. 
In Table. 1 the main characteristics of ammonia, hydrogen, methane, and gasoline are listed and compared to each other.

Table. 1: Main properties of ammonia, hydrogen, methane, and gasoline [8]

\begin{tabular}{|c|c|c|c|c|}
\hline & Gasoline & Ammonia & Hydrogen & Methane \\
\hline Formula & - & $\mathrm{NH}_{3}$ & $\mathrm{H}_{2}$ & $\mathrm{CH}_{4}$ \\
\hline Storage & Liquid & Liquid & Compressed & Compressed \\
\hline Storage temperature $(\mathrm{K})$ & 300 & 300 & 300 & 300 \\
\hline Storage pressure $(\mathrm{MPa})$ & 0.1 & 1.1 & 70 & 25 \\
\hline Density under storage conditions $\left(\frac{\mathrm{kg}}{\mathrm{m}^{3}}\right)$ & 740 & 600 & 39 & 187 \\
\hline Lower heating value $\left(\frac{\mathrm{MJ}}{\mathrm{kg}}\right)$ & 44.5 & 18.8 & 120 & 50 \\
\hline Volumetric energy density $\left(\frac{\mathrm{GJ}}{\mathrm{m}^{3}}\right)$ & 33 & 11.3 & 4.7 & 9.35 \\
\hline Stochiometric air fuel ratio by mass & 15 & 6.05 & 34.6 & 17.3 \\
\hline Auto ignition temperature & 503 & 930 & $773-850$ & 859 \\
\hline Research octane number & $90-98$ & 130 & $>100$ & 120 \\
\hline Flammability limits in air (vol. $\%)$ & $0.6-8$ & $15-28$ & $4.7-75$ & $5-15$ \\
\hline
\end{tabular}

Both ammonia and hydrogen do not lead to $\mathrm{CO}_{2}$ emissions because of the absence of carbon atoms in their chemical structure, so the combustion of those fuels produces mainly water and nitrogen. Ammonia is considered a promising energy carrier due to its high energy density and also a good hydrogen carrier. Moreover, it is also easy to store and transport thanks to the multiple production and transportation infrastructures that are well established among the international territory. Unlike hydrogen, ammonia can be stored at low pressure at ambient temperature, which reduces storage costs. In addition, it shows some suitable characteristics for use as fuel in Internal Combustion Engines (ICE) such as high octane number $(\mathrm{RON}>130)$. This allows compression ratios higher than conventional fuels and therefore possible higher thermodynamic efficiency. However, on the other hand, ammonia has slow laminar burning velocity, narrow flammability limit, low calorific value, and high minimum ignition energy, which make it not straightforwardly suitable as a fuel for internal combustion engines.

Hydrogen, instead, has low minimum ignition energy, a wide flammability limit, and a high laminar flame speed that is five times higher than methane. These characteristics allow the engine to work in lean conditions, which can lead to a substantial improvement in efficiency without incurring unacceptable cycle-to-cycle variability. Nevertheless, hydrogen has some drawbacks that allow limited use in the Spark Ignition (SI) engine. In this regard, hydrogen requires high costs for storage, has a low flash point, that can facilitate an explosion associated with air, and it is also difficult to transport due to safety issues.

Recently, despite its unfavorable characteristics, several studies are carried out on the use of ammonia as a fuel in internal combustion engines and in particular on its combustion characteristics. Duynslaegher et al. [3] have stated that a high compression ratio is mandatory in order to use $\mathrm{NH}_{3}$ as a fuel in a SI engine due to the slow laminar burning velocity of ammonia that can lead to a consistent cycle-to-cycle variability and therefore to bad efficiency. In a later study, Duynslaegher et al. have performed a numerical analysis [4] that examines the combustion characteristics of ammonia-air mixtures at elevated pressure and temperatures and air-fuel equivalence ratio around one. In this study, Konnov's combustion mechanism [5] was applied giving back a good agreement between experimental and simulated results at stoichiometric value and low pressures. This work aims to evaluate the impact of the equivalence ratio and the compression ratio on the laminar burning velocity and the NO formation. The main outcome is that both equivalence and compression ratios have a huge impact on the laminar burning velocity, instead only the equivalence ratio had a substantial effect on the NO formation. Hayakawa et al. have conducted a study on the 
laminar burning velocity and Markstein length of the ammonia-air mixtures [6] at different pressures up to $0.5 \mathrm{MPa}$ and at various equivalence ratios from 0.7 to 1.3 . The results obtained show that the laminar burning velocity reaches the maximum value at an equivalence ratio of 1.1 for all the conditions and the Markstein length increases with the equivalence ratio as well as the hydrocarbon fuels.

Anyhow pure ammonia supplied engines cannot reach the same performances as gasoline engines due to their not suitable characteristics for a SI application. For this reason, several studies have shown that the addition of hydrogen to ammonia-air mixtures can lead to an improvement of the laminar burning velocity and consequently also of the engine performances. Morch et al. have conducted a study [7] on the engine performances of ammonia/hydrogen mixtures in which they stated that these mixtures are a suitable fuel for SI engines since the addition of hydrogen can lead to an improvement of the efficiency and mean effective pressure. Lhuillier et al. have conducted an experimental study [8] on ammonia/hydrogen/air combustion in a SI engine. It is showed that the addition of hydrogen promotes the stability of the combustion and most of all improves the performance of the engine. The experiments also evidenced an increase in $\mathrm{NO}_{\mathrm{x}}$ formation due to higher combustion temperature. Recently, Wang et al. have conducted a numerical study [9] on premixed ammonia-hydrogen combustion under engine-relevant conditions. They evaluated several combustion properties of ammonia/hydrogen/air blend compared with methane/air mixtures. The results showed that, at the same compression ratio, the addition of hydrogen at least $40 \%$ in volume is mandatory to reach a laminar burning velocity similar to the hydrocarbon fuels.

Methane is widely recognized as a suitable fuel for SI engines thanks to its high knock resistance. However, it has a low laminar flame speed compared to gasoline, which in lean conditions produces a high cycle-to-cycle variability. In this regard, several studies [10-19] have analysed the performance, the characteristics of the combustion, and the emissions of methane/hydrogen/air blends. It is showed that the addition of a small quantity of hydrogen to the methane can promote combustion also in lean conditions. The addition of hydrogen also allows a reduction of the cyclic variability. The main responsible for such advantages is the hydrogen laminar flame speed that is seven times higher than the methane one.

The aim of this work is to analyse the potential of hydrogen addition to natural gas and ammonia as a solution for the abatement of the $\mathrm{CO}_{2}$ emissions of internal combustion engines. The work focuses on the 1D numerical study of a spark-ignited internal combustion engine supplied with different fuels: pure gasoline and blends of methane-hydrogen and ammonia-hydrogen. The analyses are carried out on a downsized turbocharged two-cylinder engine working in a single operating point, 9.4 bar of BMEP at $1800 \mathrm{rpm}$. This condition is frequently experienced when the engine, installed on a segment A vehicle, operates along WLTC [37]. For engine fuelling, hydrogen volume percentages up to $60 \%$ are considered, while the relative air/fuel ratio $\left(\lambda=\alpha / \alpha_{\text {st }}\right)$ is varied from 1 up to 2 . In the first section of this work, the numerical setup and the main characteristics of the considered engine are presented. In the second section, some comparisons between numerical and experimental data under pure gasoline supply are shown in order to validate the model. In the last section numerical analyses are presented, aiming at estimating the benefits and the drawbacks of considered alternative fuels in terms of engine performances, knock, $\mathrm{CO}_{2}$, and pollutant emissions. 


\section{Description of tested engine and calibration strategy}

In Table. 2 the main characteristics of the internal combustion engine under study are featured.

Table. 2: Main parameters of the engine under study

\begin{tabular}{|c|c|}
\hline \multicolumn{2}{|c|}{ Twin-cylinder VVA Turbocharged PFI Engine } \\
\hline Compression ratio & $10: 1$ \\
\hline Displaced volume, $\mathrm{cm}^{3}$ & 875.4 \\
\hline Bore, $\mathrm{mm}$ & 80.5 \\
\hline Stroke, $\mathrm{mm}$ & 86 \\
\hline Connecting rod length, mm & 136.85 \\
\hline Maximum brake power, $\mathrm{kW}$ & $63.7 @ 5500 \mathrm{rpm}$ \\
\hline Maximum brake torque, Nm & $146.7 @ 2000 \mathrm{rpm}$ \\
\hline Valve number & 4 valve/cylinder \\
\hline IVO - IVC at 2mm lift, CAD AFTDC & $342 / 356-400 / 624$ \\
\hline EVO - EVC at 2mm lift, CAD AFTDC & $134-382$ \\
\hline
\end{tabular}

As stated previously it is a downsized turbocharged two-cylinder equipped with four valves per cylinder. The engine is fuelled originally with commercial gasoline, characterized by a stoichiometric air to fuel ratio of 14.55 and a lower heating value of $42.0 \mathrm{MJ} / \mathrm{kg}$. The engine includes a pent-roof combustion chamber, fitted with a central spark-plug, having a compression ratio of 10:1, a standard ignition system, and an over-squared bore-to-stroke ratio to promote in-cylinder turbulence. The engine fits a couple of port fuel injectors, placed in the intake ducts upstream the intake valves, and a waste-gated turbocharger.

The load is controlled by a variable valve actuation (VVA) system, characterized by an electro-hydraulic device, that allows the implementation of the early intake valve closure strategy (EIVC). In this regard, the VVA device allows modifying the inlet valve closure profile to obtain the required load without the need for intake throttling in almost all operating conditions at part load. In Table. 2 the upper limit of the IVC is referred to the full lift profile, instead, the lower limit is chosen in order to obtain a satisfactory in-cylinder level of turbulence intensity and therefore to ensure stable combustion avoiding unacceptable cycleto-cycle variations.

During the experimental tests, different calibration strategies were applied depending on the engine load. In particular, the load was controlled by the waste-gate valve of the turbocharger at medium/high loads (above 10 bar of BMEP), while it was controlled at partial loads mainly by the inlet valve closure timing. The throttle valve at medium/high loads is completely open to guarantee the maximum filling of the cylinder, instead, at part loads, the throttle opening is modified to maintain the intake pressure slightly lower than the atmospheric one ( 0.98 bar). Appropriate strategies are also applied, such as combustion phasing delay and gasoline enrichment, in order to limit the knock intensity and the exhaust gas temperature at the turbine inlet. The spark advance is selected to obtain an optimal combustion phasing 8-10 CADs after TDC, in those operating conditions in which the knock intensities are acceptable, otherwise, it is properly delayed.

The calibration campaign made available an extended experimental database. In different previous studies $[23,24,25]$ the overall performances were measured in more than 280 operating points. The experimental data is utilized in this work to validate the $1 \mathrm{D}$ model in the selected operating point, namely $1800 \mathrm{rpm}$ and 9.4 bar of BMEP. 


\section{Modeling approach}

The simulation and the schematization of the engine under study are carried out in GT-Power. The engine schematization in this environment includes the whole intake and exhaust pipes systems, cylinders, intake and exhaust valves, throttle valve, and the waste-gated turbocharger. Different modeling approaches are applied depending on the phenomenon to be described. In this regard, on one hand, a 0D approach is applied for the in-cylinder processes, on the other hand, the unsteady flow inside the intake and exhaust pipes is described by a $1 \mathrm{D}$ model.

The heat transfer between the cylinder walls and the gases is computed by a Hohenberg-like correlation. For the exhaust pipes, both the convective, radiative, and conductive heat transfer modes are considered. The evaluation of both the in-cylinder and exhaust pipes heat transfer is obtained by a refined model in which a wall temperature solver, based on a finite element approach, is used.

The computation of the combustion process is based on the well-known fractal geometry theory [26,27]. A two-zone "fractal approach" is used in which the combustion chamber is divided into two-zone, respectively a burned and an unburned zone that are separated by a thin flame front. The burning rate is evaluated as:

$$
\frac{d m_{b}}{d t}=\rho_{u} A_{T} S_{L}
$$

where $\boldsymbol{A}_{T}$ is the area of the turbulent flame front, $\boldsymbol{S}_{\boldsymbol{L}}$ is the laminar flame speed and $\boldsymbol{\rho}_{\boldsymbol{u}}$ is the unburned gas density. Introducing in the above equation the area of the laminar flame front $\boldsymbol{A}_{\boldsymbol{L}}$, the following equation is obtained:

$$
\frac{d m_{b}}{d t}=\rho_{u} A_{L} S_{L} \frac{A_{T}}{A_{L}}=\rho_{u} A_{L} S_{L} \Xi
$$

where the ratio between the turbulent flame area to the laminar one is the so-called wrinkling factor, which represents the area increase of the flame front due to flame/turbulence interaction. This ratio, according to the fractal theory, can be estimated as:

$$
\frac{A_{T}}{A_{L}}=\left(\frac{\Gamma_{\max }}{\Gamma_{\min }}\right)^{D_{3}-2}
$$

where $\Gamma_{\max }$ and $\Gamma_{\min }$ are the length scales of the maximum and minimum flame wrinkling, respectively, and $D_{3}$ is the fractal dimension. The evaluation of $\Gamma_{\max }$ and $\Gamma_{\min }$ and $D_{3}$ is based on the turbulence sub-model presented in $[28,29]$. The theory behind the fractal combustion model relies on the assumption that combustion chemistry does not interact with turbulence. This means that turbulence can enhance the combustion speed only increasing the surface of the flame front. This assumption applies when the combustion regime falls within the corrugated or wrinkled flamelets regime, as classified by Borghi in [40].

A refined treatment of the laminar flame speed and the chemistry of the end gas are implemented to improve the description of the combustion process and the knock phenomenon, respectively. Appropriate laminar flame speed correlations are applied for both ammonia-hydrogen blends, taken from the work of Goldmann et al. [22], and methane- 
hydrogen blends [33]. It is worth underlining that the $\boldsymbol{S}_{\boldsymbol{L}}$ in Eq. (1) includes the effect of the flame stretch that is taken into account according to:

$$
S_{L}=S_{L, u n}-L_{b} K
$$

where $L_{b}$ is the Markstein length and $\mathbb{K}$ is the flame stretch rate. The evaluation of $L_{b}$ is grounded on correlations of global activation energies and Lewis numbers appropriate for air/gasoline, air/hydrogen [35], and air/ammonia mixtures. In the case of fuel blends, the values from pure fuel correlations are blended following the approach presented in [36]. It is worth underlining that the ignition process is not directly modeled. At the spark event, a portion of unburned gas is assumed to burn leading to a small spherical flame front placed between the spark plug electrodes. Hence, the ignitability of the air/fuel mixture is not predicted. The model only allows estimating the possibility of too slow and uncomplete combustions when the predicted laminar flame speed, including stretch effect, assumes very reduced levels. This, as shown below, mainly affect the applicability of ammonia as a fuel when the hydrogen percentage is reduced.

In order to model the knock phenomenon, the variation of the composition of the end gas caused by the auto-ignition (AI) process is described, coupled to the solution of the equations of mass and energy. The AI process is modelled following a tabulated approach to limit the computational burden. In a preliminary stage, Cantera software is used to solve the chemical reactions in a constant-volume or constant-pressure homogeneous reactor. AI process is simulated for various initial values of pressure, temperature, $\lambda$, residual content and molar or mass fraction of hydrogen over the total fuel. The outcome is an extensive auto-ignition table, in which the AI progress variable and the AI time for both low temperature and hightemperature reactions are collected. The AI progress variable is defined as a function of the time evolution of species formation enthalpies, according to $[38,39]$. The chemical kinetic model selected for the description of the chemistry of the ammonia-hydrogen blends is taken from the work of Otomo et al [20], which, in turn, is based on the scheme of Song et al. [21]; this last is developed for the oxidation of pure ammonia in the air. For methane-hydrogen blends, the well-assessed GRI mech scheme is selected [34].

A model for the evaluation of the pollutant emissions, namely $\mathrm{NO}_{\mathrm{x}}, \mathrm{CO}$, and unburned fuel, is adopted. A multi-zone approach is used to estimate the amount of $\mathrm{NO}_{\mathrm{x}}$ and $\mathrm{CO}$. On one hand, the extended Zeldovich mechanism is used to evaluate the NO kinetics [31], on the other hand, a two-step reaction scheme [32] is used to describe the CO kinetics. A refined model for the evaluation of the unburned fuel is implemented, considering both the filling/emptying of the crevices volume, the flame wall quenching, and the fuel postoxidation, as explained in a previous work of the authors [30].

\section{Numerical setup and model validation}

The validation of the 1D model will be briefly recalled in this section. This refers to engine operation with a pure gasoline supply. It is worth underlining that the 1D model has already been extensively validated in several previous works of the authors in different operating conditions, and therefore, for the sake of brevity, only the validation results related to the selected operating point are recalled.

The input data of the simulations are the experimental Brake Mean Effective Pressure (BMEP), engine rotational speed, gas temperature downstream the intercooler, lambda, and intake valve closure angle. To match the experimental load, the throttle valve opening is automatically adjusted by a PI controller. The turbocharger waste-gate is assumed completely opened. To realize the same gas temperature after the intercooler as in the experiments, the wall heat transfer within the intercooler is highly enhanced targeting the experimental datum. 
The value of the knock indicator is selected to reproduce a combustion phasing ( $\left.\mathrm{MFB}_{50 \%}\right)$ similar to the experimental data. The above-identified level of knock indicator is used as a reference for the following analyses where the engine is fuelled with ammonia-hydrogen and methane-hydrogen mixtures.

With the aim to show the model predictive capability, some comparisons between experimental data and numerical results are shown below. In Fig.1 the numerical/experimental comparisons of brake specific fuel consumption (BSFC), maximum in-cylinder pressure, and the main combustion angle parameters, namely $\mathrm{MFB}_{50 \%}$, spark advance and $\mathrm{MFB}_{10-90 \%}$ are depicted.

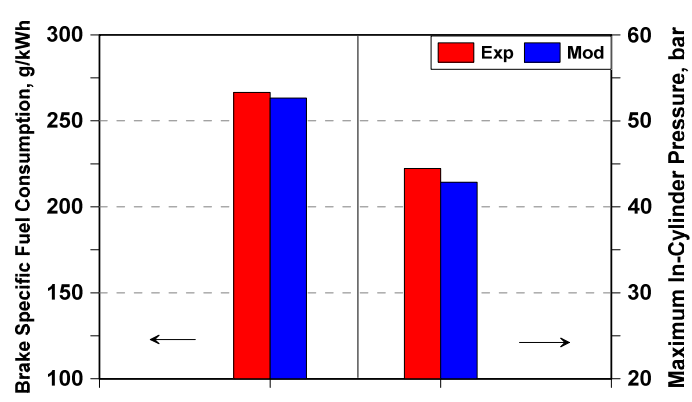

(a) BSFC-Maximum in-cylinder pressure

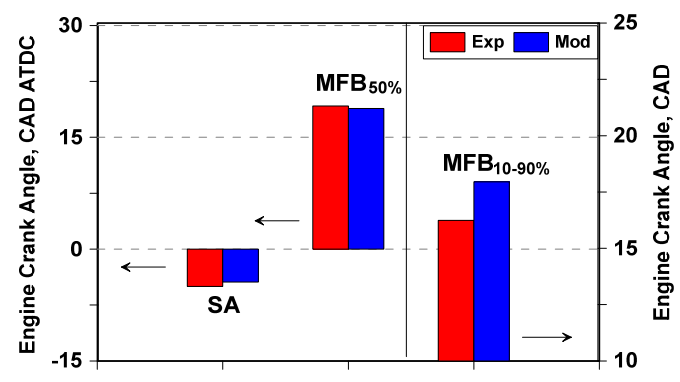

(b) SA-MFB $50 \%-\mathrm{MFB}_{10-90 \%}$

Fig.1: Numerical/experimental comparisons of BSFC, maximum in-cylinder pressure , and SA, $\mathrm{MFB}_{50 \%}$, and $\mathrm{MFB}_{10-90 \%}$

Fig.1 shows a really good agreement between the experimental and numerical data. BSFC and maximum cylinder pressure present an error of $1.2 \%$ and $4.5 \%$, respectively. Very reduced errors on the predictions of spark advance and combustion phasing emerge, below 1 degree in both cases. Some inaccuracies occur for the combustion duration, which is slightly overestimated by the model.

\section{Engine modification}

The base engine is modified to investigate the impact of the supply with the considered alternative fuels on the main engine performance. In this context, the injector placed upstream the intake valves is supplied with a mixture of ammonia-hydrogen or methane-hydrogen.

A parametric study on the effects of hydrogen content and air/fuel proportion is carried out in the selected operating condition. The air/fuel metering is modified to investigate the impact of mixture leaning, passing from 1 up to 2 with a step of 0.2 . Moreover, the simulations are performed for four hydrogen molar fractions, namely $0,0.2,0.4,0.6$ for each considered $\lambda$ level. Table. 3 summarizes, in addition to the above-mentioned levels of molar fraction, the corresponding values of mass fraction and percentage of energy stored in the hydrogen normalized by the total fuel energy.

Table. 3: Tested hydrogen-methane and hydrogen-ammonia blends

\begin{tabular}{|c|c|c|c|c|c|}
\hline & $\mathrm{H}_{2}$ molar fraction & 0.0 & 0.2 & 0.4 & 0.6 \\
\hline \multirow{2}{*}{ Methane-Hydrogen } & $\mathrm{H}_{2}$ mass fraction & 0.0 & 0.030 & 0.077 & 0.158 \\
\cline { 2 - 6 } & $\mathrm{H}_{2}$ energy fraction & 0.0 & 0.07 & 0.17 & 0.31 \\
\hline \multirow{2}{*}{ Ammonia-Hydrogen } & $\mathrm{H}_{2}$ mass fraction & 0.0 & 0.028 & 0.073 & 0.150 \\
\cline { 2 - 6 } & $\mathrm{H}_{2}$ energy fraction & 0.0 & 0.16 & 0.33 & 0.53 \\
\hline
\end{tabular}


It is important to underline that the BMEP target is obtained with different engine control logics depending on the lambda value. In particular, on one hand, for the stochiometric mixtures, the waste-gate is completely closed and the BMEP target is achieved through the adjustment of the throttle valve; instead, for lean mixtures, the throttle valve is completely opened and the turbocharger waste-gate is adjusted by a PI controller to match the BMEP target. The spark advance is adjusted to obtain the optimized combustion phasing, namely $\mathrm{MFB}_{50 \%}$ of $8 \mathrm{CAD}$ after TDC, but it is delayed automatically when the knock intensity exceeds the threshold level identified in the validation simulation.

\section{Results discussion}

\subsection{Methane-hydrogen}

In Fig. 2 are depicted the contour plots related to the global performances of the engine supplied with a blend of methane-hydrogen. Note that the parameters are represented as a function of both lambda and hydrogen mass/energy fraction.

Results with $\lambda$ greater than 1.6 are not depicted since the BMEP target is not reached even if the WG valve is fully closed. In all figures, the isoline representative of the result of gasoline stoichiometric case is highlighted with a thicker contour. Before starting the results discussion, it is worth highlighting that for all tested air/fuel proportions and fuel mixtures knock does not appear. For this reason, the $\mathrm{MFB}_{50 \%}$ attains the optimal timing of 8 degrees after TDC

The effects of $\lambda$ and $\mathrm{H}_{2}$ content on combustion speed can be appreciated through the combustion durations depicted in Fig. $\mathbf{2 c}$ and $\mathbf{2 d}$, representing the duration of the combustion in its initial stage $\left(\mathrm{MFB}_{0-10 \%}\right)$ and in its main phase $\left(\mathrm{MFB}_{10-90 \%}\right)$, respectively. They underline that, as the hydrogen fraction injected increases, the combustion speeds up. This is due to the increase of the laminar flame speed. As expected, at the same hydrogen fraction, an increase of the duration of the combustion occurs leaning the mixture, once again, due to a slowdown of the laminar flame speed. Note also that the addition of hydrogen has a major effect on the first stage of combustion rather than on the combustion core. It can be also noted from Fig. $\mathbf{2 c}$ and $\mathbf{2 d}$ that, for $\lambda$ lower than 1.4, whatever is the hydrogen content, a slightly faster combustion occurs with respect to reference gasoline case. This is a consequence of a better combustion phasing, which leads to higher values of pressure and temperature when combustion takes place and hence to higher laminar flame speeds.

Despite these benefits, Fig. 2a puts into evidence that an addition of hydrogen at the same lambda causes a reduction of the brake efficiency. This slightly decrease is caused by an increase of wall heat losses Fig. 2b, in turn due to higher combustion temperatures. Fig. 2a highlights, as expected, that the brake efficiency increases by leaning the mixture. This is promoted by more favorable thermodynamic properties of the in-cylinder gas and by lower wall heat losses. Note that the latter are normalized by the total energy introduced in the engine through the fuel blend. Heat losses in case of pure gasoline fueling (24.6\%) are smaller than the ones arising from hydrogen/methane supply. This is due to a delayed combustion phasing, required to mitigate knock intensity. A brake efficiency advantage of about $2 \%$ 
emerges in the comparison between gasoline stoichiometric fueling and configuration with full methane and $\lambda=1.4 / 1.6$.

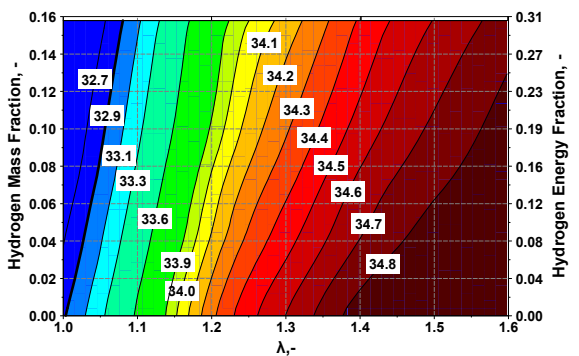

(a) Brake efficiency

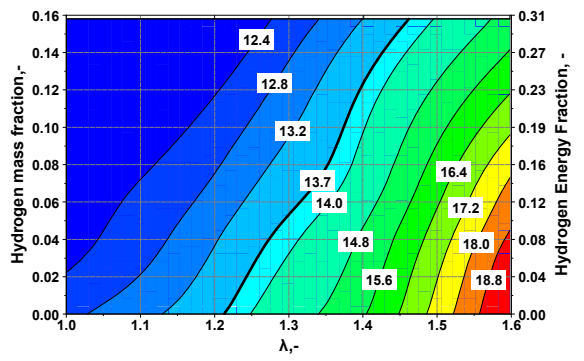

(c) $\mathrm{MFB}_{0-10 \%}$

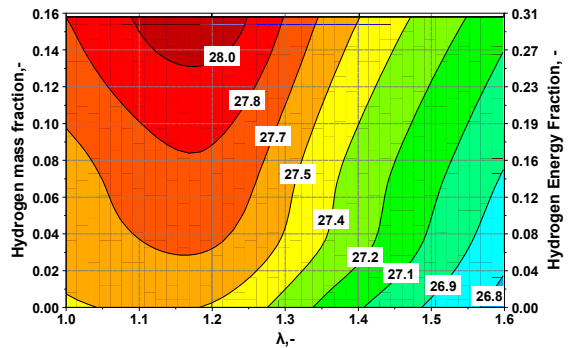

(b) Wall heat losses

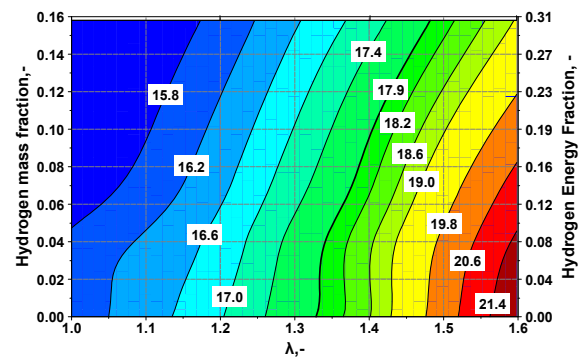

(d) MFB $_{10-90 \%}$

Fig. 2: Contour plots of Brake efficiency (-), in-cylinder wall heat losses (\%), MFB $010 \%, \mathrm{MFB}_{10-90 \%}$ $(\mathrm{CAD})$ related to methane-hydrogen mixtures.

In Fig. 3 the contour plots of brake specific emissions are reported, and more specifically they refer to $\mathrm{CO}, \mathrm{HC}$ and $\mathrm{NO}_{\mathrm{x}}$, and $\mathrm{CO}_{2}$. As expected, the $\mathrm{BSCO}$ is reduced leaning the mixture due to the great amount of oxygen introduced in the combustion chamber that helps the oxidation of the carbon monoxide. It can be seen also that the hydrogen addition does not significantly affects the emission of carbon monoxide.

The hydrogen addition abates strongly the $\mathrm{BSCO}_{2}$, increasing the $\mathrm{H} / \mathrm{C}$ ratio of the fuel mixture (greater than 4). Note also that, at same hydrogen mass fraction, the $\mathrm{CO}_{2}$ emissions are slightly decreased leaning the mixture accordingly to the efficiency increase. It is worth evidencing that $\mathrm{BSCO}_{2}$ of reference gasoline case $(784 \mathrm{~g} / \mathrm{kWh})$ is well above the levels arising from hydrogen/methane fuelling, due to the unfavourable $\mathrm{H} / \mathrm{C}$ ratio of the gasoline $(\sim 2)$.

The emission index of the unburned hydrocarbons, depicted in Fig. 3c, presents a reduction as the hydrogen content increases. This is explained by higher in-cylinder temperatures, promoted by faster combustions, which determine a more effective post-oxidation of unburned hydrocarbons. Leaning the mixture, with a mechanism opposite to the one above introduced, determines an increase of unburned hydrocarbons. In the comparison with gasoline case, generally hydrogen/methane fuelling leads to higher $\mathrm{uHC}$ emissions. This is mainly due to a slower post-oxidization chemistry of methane compared to the gasoline one. Fig. 3d underlines that $\mathrm{BSNO}_{\mathrm{x}}$ reaches the maximum value at $\lambda=1.2$ and at the highest value of hydrogen content. This is favoured by excess oxygen availability and high in-cylinder temperature. A stoichiometric metering, despite of the highest temperatures, does not favour $\mathrm{NO}_{\mathrm{x}}$ formation due to lack of oxygen. On the contrary, a mixture leaning determines a $\mathrm{NO}_{\mathrm{x}}$ 
reduction thanks to in-cylinder temperature lowering. $\mathrm{NO}_{\mathrm{x}}$ production under stoichiometric conditions is comparable to the gasoline case.

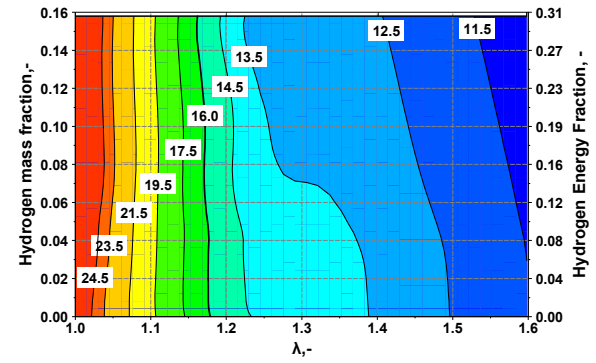

(a) BSCO

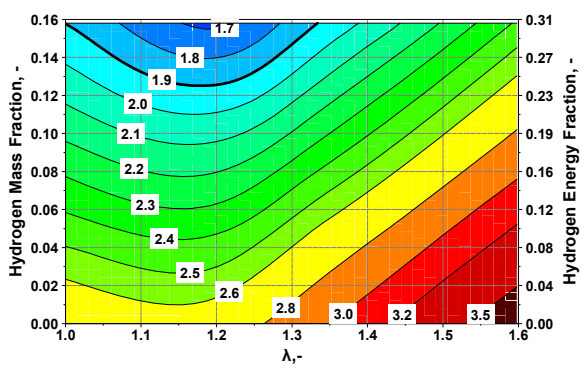

(c) BSHC

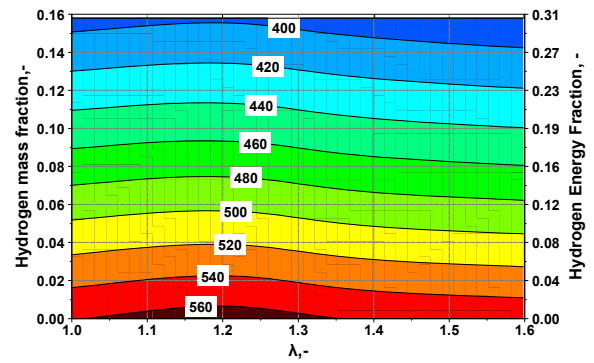

(b) $\mathrm{BSCO}_{2}$

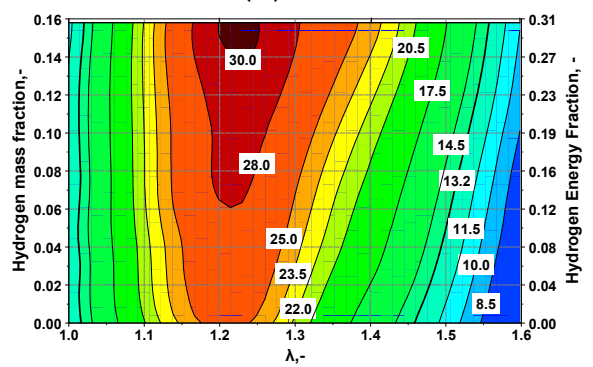

(d) BSNO $_{x}$

Fig. 3: Contour plots of engine-outexhaust emissions $(\mathrm{g} / \mathrm{kWh})$ related to methane-hydrogen mixtures.

\subsection{Ammonia-hydrogen}

In a manner similar to hydrogen/methane analysis, in Fig. 4 the contour plots of brake efficiency (a), wall heat losses (b) and combustion durations (c-d) are depicted as a function of air/fuel proportion and hydrogen content. In addition, the contour plot of $\mathrm{MFB}_{50 \%}$ and the Borghi diagram evaluated in the middle of the combustion evolution are depicted in Fig. $4 \mathbf{e}$ and 4f, respectively. The levels related to the gasoline stoichiometric case, once again, are highlighted with a thicker line. Note also that only the results of analyses where the BMEP target is reached are represented. At $\lambda=2$, even fully closing the turbocharger waste-gate, the load level is not attained. In conditions of ultra-lean mixture and small hydrogen mass fractions, the desired load is not reached due to excessively slow combustions.

Fig. 4c and 4d put into evidence that the addition of hydrogen to ammonia substantially improves the burning velocity both at the beginning and in the core of combustion process. Note also that leaning the mixture causes an increase of the duration of the combustion due to the slowdown of the laminar burning velocity. Note that the duration of initial combustion phase is $2 / 3$ times greater than the one of reference gasoline fueling when hydrogen doping is null or reduced and the mixture is lean. This let foresee the possibility of unstable or excessively slow combustions if those conditions would have been reproduced on the real engine. It is worth noting that, in all tested configurations, both $\mathrm{MFB}_{0-10 \%}$ and $\mathrm{MFB}_{10-90 \%}$ are well above than the gasoline combustion durations. Another interesting outcome of the presented analyses is the observation of the combustion regime. This can be investigated through the observation of Borghi diagram. As known, this compares, in logarithmic scales, combustion and turbulence characteristic scales of velocity and length ${ }^{1}$. The numerical results

${ }^{1} \delta_{\mathrm{f}}$ flame front thickness, $\mathrm{L}_{\mathrm{I}}$ turbulence integral length scale, $\mathrm{u}$ ' turbulence intensity. 
put into evidence that the combustion regime in case of ammonia and ammonia/hydrogen blends falls within the corrugated flamelets regime. This is consistent with fractal model theoretical background, confirming the appropriateness of choosing this approach in the presented study.

Fig. 4a underlines that the brake efficiency at the same lambda slightly reduces as the hydrogen mass fraction rises. The explanation of this result does not relay, in this case, in an increase of the heat losses. Those, on the contrary, slightly reduces when hydrogen increases (Fig. 4b). The reason of such behavior as well as of the brake efficiency reduction is the onset of knock, promoted by faster burning speed, that obliges to delay the combustion phasing (Fig. 4e). Fig. 4a puts into evidence that the brake efficiency increases leaning the mixture, and this is due to the improvement of thermodynamics properties of in-cylinder mixture. An advance of about $1 \%$ in brake efficiency with $\lambda=1.6 / 1.8$ and minimum allowed hydrogen addition emerges with respect to the gasoline case. For the stoichiometric fuel metering, an efficiency level similar to the gasoline case occurs.

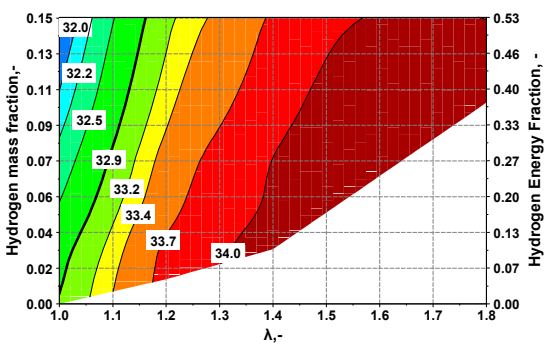

(a) Brake efficiency

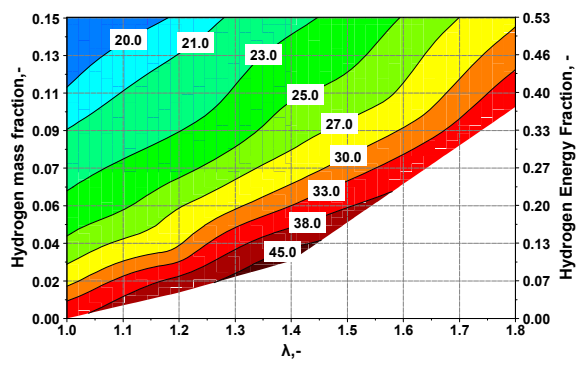

(c) $\mathrm{MFB}_{0-10 \%}$

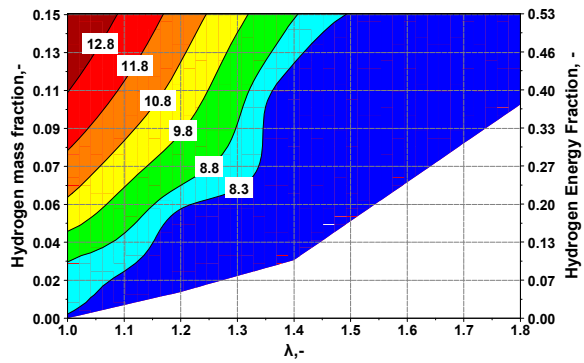

(e) $\mathrm{MFB}_{50 \%}$

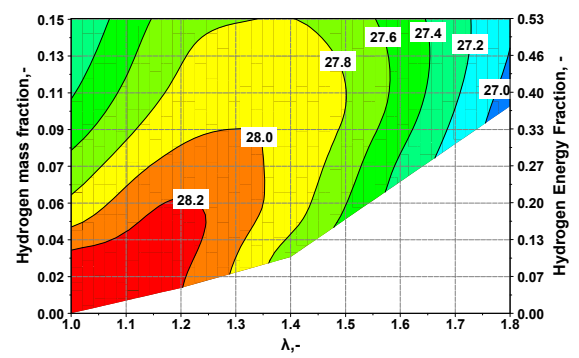

(b) Wall heat losses

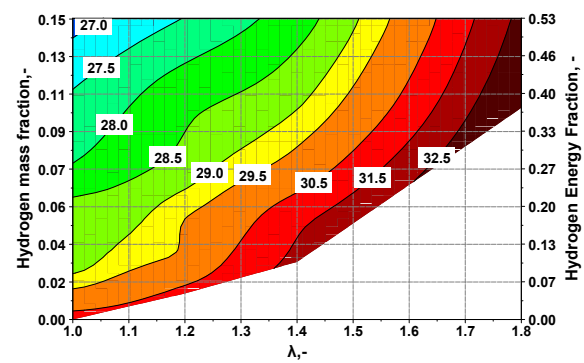

(d) $\mathrm{MFB}_{10-90 \%}$

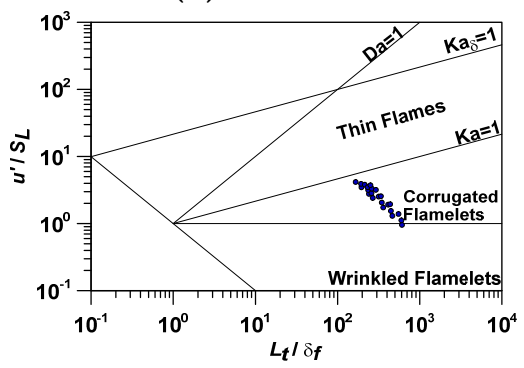

(f) Borghi Diagram

Fig. 4: Contour plots of Brake efficiency (-), in-cylinder wall heat losses (\%), $\mathrm{MFB}_{0-10 \%}, \mathrm{MFB}_{10-90 \%}$ (CAD), $\mathrm{MFB}_{50 \%}(\mathrm{CAD}$ after TDC) and Borghi diagram related to ammonia-hydrogen mixtures. 
In Fig. 5, the plots of the pollutant emissions, namely unburned ammonia and nitrogen oxides, are depicted. The hydrogen addition helps in reducing the unburned ammonia thanks to a faster combustion, which leads to higher in-cylinder temperatures and consequently to a better post-oxidation. With a similar mechanism, at the same hydrogen mass fraction, leaning the mixture leads to an increase of unburned ammonia, especially with $\lambda$ greater than 1.2. Fig. 5b highlights that nitrogen oxides mainly correlate with air/fuel proportion. The maximum value is reached at both high hydrogen mass fraction and at $\lambda$ of about 1.2/1.3. This is due to excess oxygen availability and high in-cylinder temperatures. Moving towards leaner mixtures, $\mathrm{BSNO}_{\mathrm{X}}$ reduces thanks to lower combustion temperatures. Hydrogen addition seems to not drastically affect nitrogen oxides production.

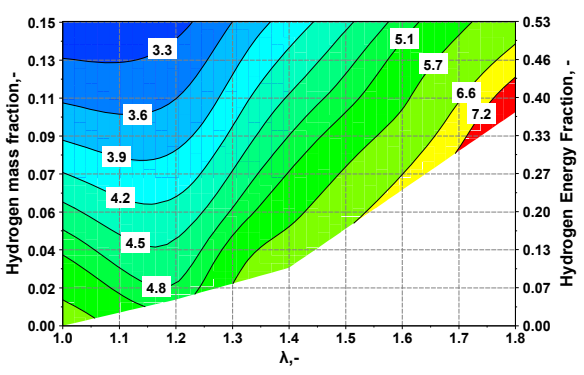

(a) $\mathrm{BSNH}_{3}$

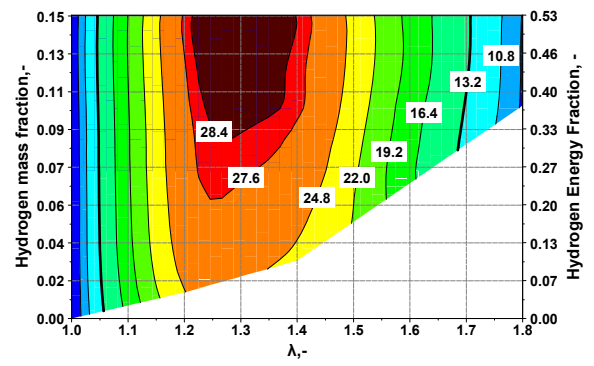

(b) BSNOx

Fig. 5: Contour plots of engine-out exhaust emissions ( $\mathrm{g} / \mathrm{kWh}$ ) related to ammonia-hydrogen mixtures.

As a final remark, it is worth highlighting that the results presented in this section, although appear reasonable and in line with theoretical expectations, would require an experimental verification, especially under the viewpoint of mixture ignitability. As is well known, one of the major drawbacks in the use of ammonia as a fuel is the need of high energy to ignite. However, the blending with hydrogen should help in overcoming this issue, making feasible the adoption of ammonia as fuel in real engine applications.

\section{Conclusions}

In this work an assessment of the potential of hydrogen addition to natural gas or to ammonia is presented as a solution towards low- or zero- carbon fuel for the supply of spark-ignition engines. Several engine relevant parameters were investigated as a function of both air-fuel proportions and hydrogen content in fuel mixture. The study concerned a small turbocharged SI engine operating at partial load, namely $1800 \mathrm{rpm}$ and 9.4 bar of BMEP.

A 1D model of the engine under study have been developed in GT-Power environment. It is provided with several sub-models of turbulence, combustion, heat transfer and knock, validated in the previous works of the authors.

In a first stage, a validation of the model in case of stoichiometric gasoline is recalled. Subsequently, the changes made to the engine model are presented, needed to investigate the effects of methane-hydrogen and ammonia-hydrogen blends.

Analyses showed that the addition of hydrogen for both methane and ammonia has a positive effect on the duration of the combustion, especially in its initial phase. The addition of hydrogen led to a slightly lower brake efficiency. This is explained by higher wall heat losses, in case of methane/hydrogen fueling, and by suboptimal combustion phasing, due to knock onset, in case of ammonia/hydrogen supply. Whatever is the fuel, slight brake efficiency improvements $(1 \div 2 \%)$ emerge leaning the mixture and minimizing the amount of hydrogen. With reference methane fueling, hydrogen addition allows to drastically reduce the $\mathrm{CO}_{2}$ 
emissions. Whatever is the fuel, lambda increase helps in bating the $\mathrm{NO}_{\mathrm{x}}$, but, on the other hand, also causes higher unburned fuel.

As a final remark, it is worth mentioning that some additional concerns need to be addressed to verify the practical applicability of ammonia as a fuel in internal combustion engine. Some of the most critical issues could be the aggressivness of ammonia on both engine mechanical components and fuel system, and the potential chemical hazard on human health in case of direct contact with this fuel.

\section{References}

1. Dagoumas, A. S., Papagiannis, G. K., \& Dokopoulos, P. S. An economic assessment of the Kyoto Protocol application. Energy Policy, 34 (2006): 26-39.

2. J.Rogelj, M. den Elzen, N. Hohne, T. Fransen, H.Fekete, H. Winkler, R. Schaeffer, F. Sha, K, Riahi, M. Meinshausen, Paris Agreement climate proposals need a boost to keep warming well below 2 C. Nature 534.7609 (2016): 631-639.

3. C.Duynslaegher, H. Jeanmart, J. Vandooren, Proceedings of the Combustion Institute 32.1 (2009): 1277-1284.

4. C. Duynslaegher, H. Jeanmart, J. Vandooren, Fuel 89.11 (2010): 3540-3545.

5. A. Konnov, In Proceedings of the 28-th symposium (int.) on Combustion, Edinburgh (2000)

6. A. Hayakawa, T. Goto, R. Mimoto, Y. Arakawa, T. Kudo, H. Kobayashi, Fuel 159 (2015): 98-106.

7. C.S. Morch, A. Bjerre, M.P Gøttrup, S.C. Sorenson, J. Schramm, Fuel 90.2 (2011): 854864

8. C. Lhullier, P. Brequigny, F. Contino, C. Mounaïm-Rousselle, Fuel 269 (2020): 117448.

9. D. Wang, C. Ji, S. Wang, J. Yang, Z. Wang, International Journal of Hydrogen Energy 46.2 (2021): 2667-2683.

10. L.M. Das, R. Gulati, P.K. Gupta, International Journal of Hydrogen Energy, 25.8 (2000): 783-793

11. C.G Bauer, T.W. Forest, International Journal of Hydrogen Energy, 26.1 (2001): 55-70

12. Z. Huang, J. Wang, B. Liu, K. Zeng, J. Yu, D. Jiang, Fuel, 86.3 (2007): 381-387

13. S. Orhan Akansu, N. Kahraman, B. Çeper, International Journal of Hydrogen Energy, 32.17 (2007): 4279-4284

14. T. Thurheer, P. Soltic, P. Dimopoulos Eggenschwiler, International Journal of Hydrogen Energy, 34.5 (2009): 2494-2503

15. R.T.E Hermanns, A.A Konnov, R.J.M. Bastiaans, L.P.H. de Goey, K. Lucka, H. Köhne, Fuel, 89.1 (2010): 114-121

16. O. Laget, S. Richard, D. Serrano, D. Soleri, International Journal of Hydrogen Energy, 37.15 (2012): 11514-11530

17. A. Mariani, B. Morrone, A. Unich, Fossil fuel and the environment 2 (2012): 17-36

18. C. E. Okafor, A. Hayakawa, Y. Nagano, T. Kitagawa, International Journal of Hydrogen Energy, 39.5 (2014): 2409-2417

19. F. Catapano, S. Di Iorio, P. Sementa, B.M. Vaglieco, Energy, 117 (2016): 378-387

20. J. Otomo, M. Koshi, T. Mitsumori, H. Iwasaki, K. Yamada, International Journal of Hydrogen Energy, 43.5 (2018): 3004-3014

21. Y. Song, H. Hashemi, JM. Christensen, C. Zou, P. Marshall, P. Glarborg, Fuel, 181 (2016): 358-365

22. A. Goldmann, F. Dinkelacker, Fuel 224 (2018): 366-378.

23. F. Bozza, V. De Bellis, L. Teodosio, International Journal of Engine Research, 18.8 (2017): 810-823. doi: $10.1177 / 1468087416674653$ 
24. L. Teodosio, V. De Bellis, F. Bozza, and D.Tufano, SAE Technical Paper 2017-24-0015, 2017, doi: 10.4271/2017-24-0015.

25. F. Bozza, V. De Bellis, P. Giannattasio, L. Teodosio, L. Marchitto, SAE International Journal of Engine 10.4 (2017):2141-2153, doi: 10.4271/2017-24-0014.

26. F. Gouldin, Combustion and Flame 68.3 (1987):249-66, doi: 10.1016/00102180(87)90003-4.

27. J. Gatowsky, J.B. Heywood, Combust Flame 56.1 (1984):71-81; doi: 10.1016/00102180(84)90006-3.

28. V. De Bellis, F. Bozza, S. Fontanesi, E. Severi, F. Berni, SAE International Journal of Engine 9.1 (2016):506-519, doi:10.4271/2016-01-0545.

29. F. Bozza, L. Teodosio, V. De Bellis, S. Fontanesi, A. Iorio, SAE Technical Paper 201801-0856, 2018, doi: 10.4271/2018-01-0856.

30. E. Malfi, V. De Bellis, F. Bozza, A. Cafari, G. Caputo, J. Hyvönen, International Journal of Engine Research, 2021, doi: 10.1177/14680874211005063.

31. V. De Bellis, E. Malfi, L. Teodosio, P. Giannattasio, F. Di Lenarda, SAE International Journal of Engine 12.3 (2019): 251 - 270, doi: 10.4271/03-12-03-0018.

32. G. Lavoie, J.B. Heywood, J.C. Keck, Combustion Science and Technology 1.4 (1970): 313-326, doi:10.1080/00102206908952211.

33. S. Bougrine, S. Richard, A. Nicolle, D. Veynante, International Journal of Hydrogen Energy, 36.18 (2011): 12035-12047

34. Bowman, C., Hanson, R., Song, S., Gardiner, W., Lissianski, V., and Qin, Z., What's New in GRI-Mech 3.0. Available at: http://combustion.berkeley.edu/grimech/version30/text30.html.

35. G.K. Giannakopoulos, A. Gatzoulis, C.E Frouzakis, M.Matalon, A.G. Tomboulides, Combustion and Flame 162 (4):1249- 1264, 2015, doi: 10.1016/j.combustflame.2014.10.015.

36. F. Dinkelacker, B. Manickam, S.P.R Muppala, Combustion and Flame, 158 (9), 17421749, 2011, doi: 10.1016/j.combustflame.2010.12.003.

37. F. Bozza, V. De Bellis, L. Teodosio, D. Tufano, SAE Technical Paper 2018-37-0008

38. H. Lehtiniemi, Y. Zhang, R. Rawat, F. Mauss, SAE technical paper, No. 2008-01-0957.

39. T. Lucchini, A. Della Torre, G. D'Errico, A. Onorati, Applied Energy, 247 (2019)

40. Peters, Norbert. "Turbulent combustion." (2001) 